\title{
Early prediction of autoimmune (type 1) diabetes
}

\author{
Simon E. Regnell ${ }^{1}$ • Åke Lernmark ${ }^{1}$ \\ Received: 12 January 2017 / Accepted: 27 March 2017 / Published online: 26 May 2017 \\ (C) The Author(s) 2017. This article is an open access publication
}

\begin{abstract}
Underlying type 1 diabetes is a genetic aetiology dominated by the influence of specific HLA haplotypes involving primarily the class II $D R-D Q$ region. In genetically predisposed children with the $D R 4-D Q 8$ haplotype, exogenous factors, yet to be identified, are thought to trigger an autoimmune reaction against insulin, signalled by insulin autoantibodies as the first autoantibody to appear. In children with the $D R 3-D Q 2$ haplotype, the triggering reaction is primarily against GAD signalled by GAD autoantibodies (GADA) as the firstappearing autoantibody. The incidence rate of insulin autoantibodies as the first-appearing autoantibody peaks during the first years of life and declines thereafter. The incidence rate of GADA as the first-appearing autoantibody peaks later but does not decline. The first autoantibody may variably be followed, in an apparently non-HLA-associated pathogenesis, by a second, third or fourth autoantibody. Although not all persons with a single type of autoantibody progress to diabetes, the presence of multiple autoantibodies seems invariably to be followed by loss of functional beta cell mass and eventually by dysglycaemia and symptoms. Infiltration of mononuclear cells in and around the islets appears to be a late phenomenon appearing in the multiple-autoantibody-positive with dysglycaemia. As our understanding of the aetiology and pathogenesis of type 1 diabetes advances, the improved capability for early prediction should guide new strategies for the prevention of type 1 diabetes.
\end{abstract}

Electronic supplementary material The online version of this article (doi:10.1007/s00125-017-4308-1) contains a slideset of the figures for download, which is available to authorised users.

Åke Lernmark

ake.lernmark@med.lu.se

1 Department of Clinical Sciences, Lund University/CRC, Skåne University Hospital, Jan Waldenströms gata 35, SE-20502 Malmö, Sweden
Keywords Autoimmunity · Beta cells, diabetes mellitus · Glutamic acid decarboxylase autoantibodies $\cdot$ HLA $\cdot$ Insulin autoantibodies $\cdot$ Insulin secretion $\cdot$ Insulinoma-associated antingen-2 autoantibodies $\cdot$ Next-generation sequencing . Review $\cdot$ Type 1 diabetes $\cdot \mathrm{ZnT} 8$ autoantibodies

$\begin{array}{ll}\text { Abbreviations } \\ \text { GADA } & \text { GAD autoantibodies } \\ \text { IA-2A } & \text { Insulinoma-associated antigen-2 autoantibodies } \\ \text { IAA } & \text { Insulin autoantibodies } \\ \text { NGS } & \text { Next-generation sequencing } \\ \text { TEDDY } & \text { The Environmental Determinants of Diabetes in } \\ & \begin{array}{l}\text { the Young } \\ \text { ZnT8A }\end{array} \\ \text { Zinc transporter } 8 \text { autoantibodies }\end{array}$

\section{Introduction}

Predicting and staging autoimmune (type 1) diabetes Type 1 diabetes is a chronic disease in which genetic predisposition, coupled with environmental influences predominantly early in life, induces pancreatic beta cell autoimmunity eventually resulting in both loss of function and destruction. The loss of beta cells leads to gradually diminishing insulin production, loss of blood sugar control and subsequent dependence on exogenous insulin administration; risk of developing longterm complications ensues.

The aetiology of beta cell autoimmunity is still unclear. Once beta cell autoimmunity has been established, the progression towards clinical type 1 diabetes may be classified into three stages: (1) asymptomatic beta cell autoimmunity with normoglycaemia; (2) asymptomatic beta cell autoimmunity with dysglycaemia and (3) symptomatic type 1 diabetes (Fig. 1) [1]. The sequence of events from autoimmunity to 


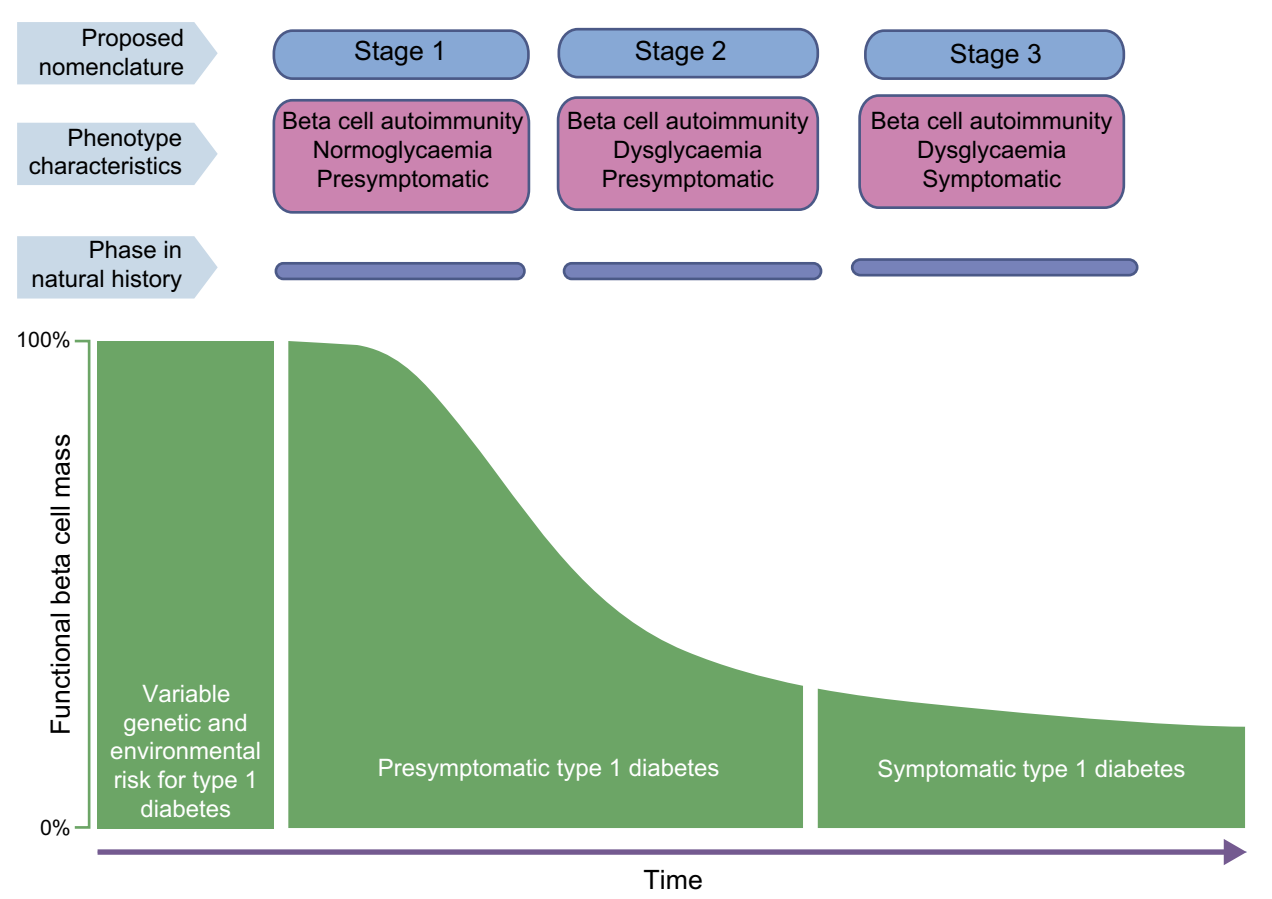

Fig. 1 Proposed staging of type 1 diabetes. The aetiology is represented by a variable genetic and environmental risk. The pathogenesis is represented by three stages. In stage 1, beta cell autoantibodies are persistent, normoglycaemia prevails and there are no symptoms. During stage 2, the number of beta cell autoantibodies may affect the pathogenesis to induce dysglycaemia but there are still no diabetes symptoms. In stage 3 , beta cell autoantibodies are still prevalent (some of them may have been lost) and there are symptoms of diabetes. The staging of type 1 diabetes pathogenesis was proposed by Insel et al [1] and the figure is adapted with permission from Insel et al [1]. (C) 2015 The American Diabetes Association

variants of other genes making smaller individual contributions. It is also worth noting that some genetic factors may be important to the appearance of a first islet autoantibody, reflecting a triggering of beta cell autoimmunity rather than diabetes as such [11].

The HLA region in type 1 diabetes aetiology and pathogenesis The HLA region on chromosome $6 \mathrm{p} 21$ is essential to the adaptive immune system. It comprises the class I region at the telomeric boundary, the class II region at the centromeric boundary and the class III region in between (Fig. 2). The HLA region contains over 250 genes, spanning some $4 \mathrm{Mbp}$, and is the most polymorphic part of the genome [12]. Indeed, polymorphism and pronounced linkage disequilibrium in the HLA region have provided significant challenges in identifying associations between HLA variants and a first-appearing beta cell autoantibody $[2,3]$.

HLA class II molecules typically present exogenous antigens to $\mathrm{T}$ lymphocytes and consist of heterodimers encoded by genes at the HLA-DR, HLA-DQ and HLA-DP loci (Fig. 2). Certain variants in all three loci can influence the risk for a first beta cell autoantibody and type 1 diabetes $[2,3,13]$. Particular combinations of HLA-DRB1, $-D Q A 1$ and $-D Q B 1$ alleles can strongly increase or decrease the risk of type 1 diabetes. For example, HLA-DRBI*04 combined with $D Q A 1 * 03 D Q B 1 * 03: 02$ confers high risk whereas $H L A$ - tibility to type 1 diabetes [10]. Variations in the HLA region account for about half of the familial genetic risk, with 
Fig. 2 Map of the $H L A D R-D Q$ $D P$ complex region on human chromosome 6 , with the class II region shown in greater detail below

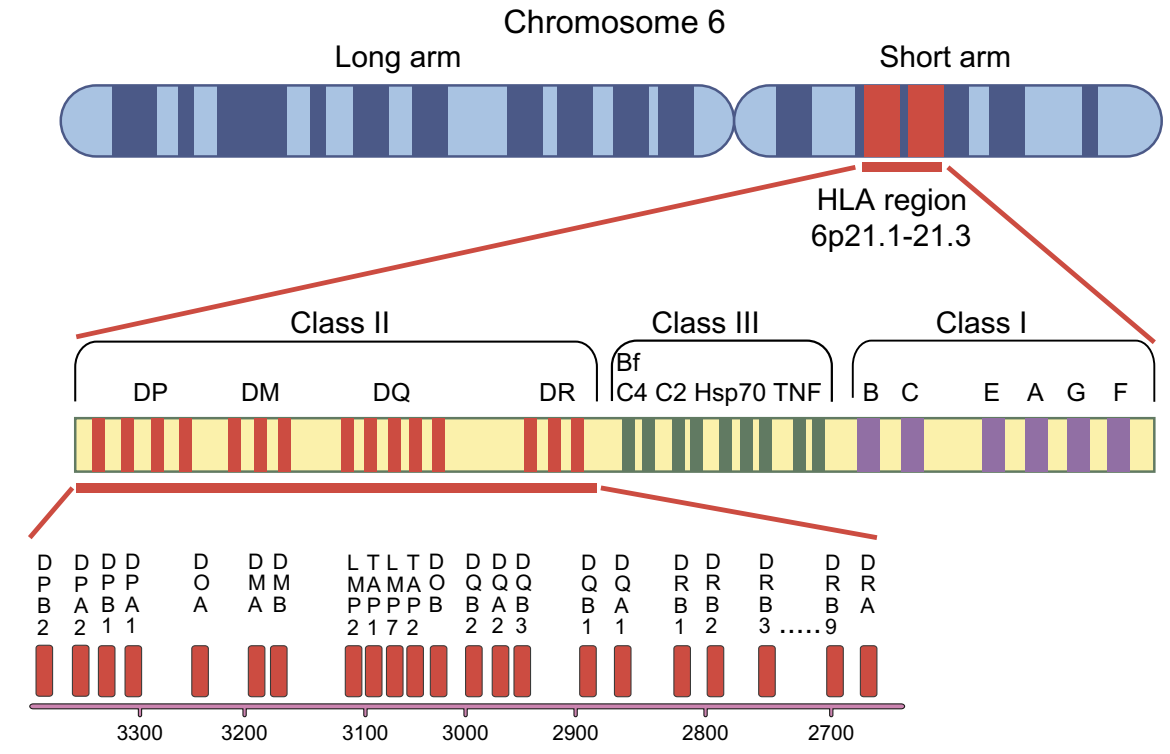

$D R B 1 * 04$ combined with $D Q A 1 * 03-D Q B 1 * 03: 01$ does not $[14,15]$.

Intuitively, HLA class II heterodimers are important not only to the risk for autoimmune type 1 diabetes as such but also more specifically to both aetiology and pathogenesis (Fig. 1). It is easy to imagine a trigger that is related to a DQ8 heterodimer inducing an autoimmune reaction against proinsulin, reflected in IAA as the first-appearing beta cell autoantibody [2]. Similarly, another trigger may be using the DQ2 heterodimer to induce an autoimmune reaction against GAD65, reflected in GADA [2]. While HLA class II heterodimers are closely related to the aetiology, HLA's contribution to the pathogenesis cannot be excluded. If beta cell autoimmunity is marked by one beta cell autoantibody only, the risk of progression to clinical onset is low (1:10) [16-18]. The appearance of a second, third or fourth autoantibody, be it IAA, GADA, insulinoma-associated antigen-2 autoantibodies (IA-2A) or zinc transporter 8 autoantibodies (ZnT8A; including autoantibodies against any of the three variants of this transporter, having either $\mathrm{W}, \mathrm{R}$ or $\mathrm{Q}$ at position 325 ), markedly increases the risk (8:10) [18-20]. Once a first beta cell autoantibody has appeared, the appearance of a second does not seem to be associated with HLA [3]. It is therefore anticipated that $H L A-D R-D Q$ will be related to any of the four islet autoantibodies at the time of clinical onset [21-24].

$D R B 1 * 03: 01-D Q A 1 * 05: 01-D Q B 1 * 02: 01$ is the most common haplotype, found in $34 \%$ and $12.5 \%$ of individuals with and without type 1 diabetes, respectively [25]. Children with the high-risk $D R B 1 * 03: 01-D Q A 1 * 05: 01-D Q B 1 * 02: 01 /$ $D R B 1 * 04: 01-D Q A 1 * 03: 01-D Q B 1 * 03: 02$ genotype have a $5 \%$ incidence of diabetes by 15 years of age [26]. HLA genotypes in the high-risk Scandinavian countries are similar but genetic differences between the countries prevail [27]. In
Sweden, the Better Diabetes Diagnosis (BDD) study HLAtyped nearly 4000 individuals newly diagnosed with type 1 diabetes below 18 years of age and found that nine genotypes accounted for $67 \%$ of all diabetic individuals compared with $16 \%$ of the population (Table 1). All nine genotypes were statistically significantly associated with type 1 diabetes. More importantly, $89 \%$ of all 3500 children with type 1 diabetes had at least one copy of either the $D Q 8$ or the $D Q 2$ haplotype.

The importance of the HLA Class II region to the aetiology and pathogenesis of type 1 diabetes calls for high-resolution genetic analyses of the region to be combined with functional assays. The interpretation that type 1 diabetes has two different aetiologies based on a single report [2] requires further studies not only of the genetic aetiology but also of candidate environmental triggers. The notion that one aetiological trigger is associated with $D R 4-D Q 8$ and concurrent IAA and the other is associated with $D R 3-D Q 2$ and GADA requires better understanding of the HLA region. Once the beta cell autoimmune reaction is established, the pathogenesis includes spreading of the autoimmunity to additional autoantigens. Using next-generation sequencing (NGS), an integrated genotyping system of exons 1-4 was developed to type all alleles of DRB1, DRB3, DRB4 and DRB5 [28, 29] (Fig. 2). NGS typing of children with and without type 1 diabetes revealed that the association between type 1 diabetes and $D R B 1 * 03: 01: 01$ was affected by $D R B 3 * 01: 01: 02$ and $D R B 3 * 02: 02: 01$ [30, 31].

MHC class I molecules present antigens to lymphocytes from within the cell and are encoded at the HLA-A, HLA-B and $H L A-C$ loci. Some MHC class I variants affect the risk of type 1 diabetes, even after adjusting for linkage disequilibrium to MHC class II haplotypes [32]. HLA-B*39:06 was the class I 
Table $1 H L A-D Q$ genotypes conferring risk for type 1 diabetes

\begin{tabular}{|c|c|c|c|c|c|}
\hline Genotype & $\begin{array}{l}\text { Diabetic } \\
\text { individuals }(n)\end{array}$ & $\begin{array}{l}\text { Diabetic } \\
\text { individuals (\%) }\end{array}$ & $\begin{array}{l}\text { Non-diabetic } \\
\text { individuals }(\%)\end{array}$ & OR & $p$ value \\
\hline \multicolumn{6}{|l|}{ High-risk HLA } \\
\hline$D Q 2 / 8$ & 957 & 27.4 & 3.5 & 10.4 & $<0.00000001$ \\
\hline$D Q 8 / 8$ & 355 & 10.1 & 1.7 & 6.7 & $<0.00000001$ \\
\hline$D Q 6.4 / 8$ & 170 & 4.9 & 1.2 & 4.2 & $<0.00000001$ \\
\hline$D Q 5.1 / 8$ & 312 & 8.9 & 2.7 & 3.5 & $<0.00000001$ \\
\hline$D Q 4 / 8$ & 154 & 4.4 & 1.4 & 3.4 & $<0.00000001$ \\
\hline$D Q 2 / 2$ & 167 & 4.8 & 1.7 & 3.0 & $<0.00000001$ \\
\hline$D Q 2 / 9$ & 36 & 1.0 & 0.5 & 2.3 & $<0.000005$ \\
\hline$D Q 6.3 / 8$ & 108 & 3.1 & 2.0 & 1.6 & $<0.000005$ \\
\hline$D Q 2 / 6.4$ & 73 & 2.1 & 1.3 & 1.6 & $<0.000005$ \\
\hline Subtotal & 2332 & 66.7 & 16.0 & & \\
\hline \multicolumn{6}{|l|}{ Neutral-risk HLA } \\
\hline 11 genotypes & & & & $0.6-1.8$ & NS \\
\hline Subtotal & 482 & 13.8 & 13.0 & & \\
\hline \multicolumn{6}{|l|}{ Low-risk HLA } \\
\hline 32 genotypes & & & & $0.05-1.0$ & HSNA \\
\hline Subtotal & 468 & 13.3 & 46.3 & & \\
\hline \multicolumn{6}{|l|}{ No-risk HLA } \\
\hline Many genotypes & & & & NA & \\
\hline Subtotal & 217 & 6.2 & 31.8 & & \\
\hline Total & 3499 & 100 & 100 & & \\
\hline
\end{tabular}

Details are available in electronic supplementary material Table 1 in [127]

13/32 of these genotypes contained $D Q 2$ or $D Q 8$

HSNA, highly significant negative associations allele most widely associated with type 1 diabetes risk, whereas $H L A-B * 57: 01$ decreases the risk [33]. Variation in class I molecules may affect age at diabetes onset rather than the absolute risk of disease [34].

The HLA class III region is genetically dense and codes for several proteins important to the immune system, such as complement factors and TNF- $\alpha$ [12]. Earlier studies of candidate genes provided disparate results [34], although a more recent genome-wide association study reported associations after adjustment for linkage disequilibrium [35]. Recent analyses in The Environmental Determinants of Diabetes in the Young (TEDDY) study, testing whether complement gene SNPs were associated with a first-appearing autoantibody, revealed three SNPs possibly contributing [36].

\section{Non-HLA genes affecting susceptibility to type 1 diabetes} Non-HLA variants may modify disease risk only in individuals with certain HLA genotypes [37]. Many of these genes are implicated in immune system regulation in particular and beta cell function less often [38, 39]. The non-HLA genes having the strongest influence on type 1 diabetes risk are INS, PTPN22 and IL2RA [40].
The association of non-HLA genes with a first-appearing beta cell autoantibody has been tested. The risk for IAA as first autoantibody was associated with INS, $S H 2 B 3, E R B B 3$, RGS1 and PTPN22 while GADA as first autoantibody was associated with CCR7, SH2B3, TNFAIP3 and CD226 [11]. Discovering how these genetic factors contribute to the triggering mechanisms of beta cell autoimmunity provides a challenge.

Some genetic susceptibility variants are shared with other autoimmune disorders, including coeliac disease and Crohn's disease [41]. Known shared loci between type 1 diabetes and rheumatoid arthritis, psoriasis and coeliac disease are concordant, whereas more than half of the SNPs influencing the risk of type 1 diabetes are discordant with genes influencing risk of inflammatory bowel disease and ankylosing spondylitis [42].

INS codes for preproinsulin, which is converted by peptidases to proinsulin and insulin. Polymorphisms of INS have the strongest association with type 1 diabetes among nonHLA genes [40]. INS is unique among susceptibilityenhancing genes as it also codes for a known autoantigen [11].

PTPN22 encodes a protein tyrosine phosphatase involved in T cell receptor signalling. A gain-of-function mutation proposed to promote autoreactive $\mathrm{T}$ cell survival is associated 
with type 1 diabetes, as well as autoimmune thyroiditis, Crohn's disease, multiple sclerosis, rheumatoid arthritis and systemic lupus erythematosus [40, 43]. Most established susceptibility genes seem to act multiplicatively with other loci on the risk of disease, except for the joint effect of HLA and PTPN22 [44]. The minor allele of PTPN22 is associated with GADA [37].

IL2RA encodes IL-2 receptor subunit $\alpha$, which is expressed on lymphocytes. It has also been associated with multiple sclerosis and systemic lupus erythematosus [40].

\section{Environmental factors}

Environmental factors may trigger either beta cell autoimmunity and the appearance of a first autoantibody [2] or the progression to clinical onset of type 1 diabetes. There is large geographic variation in type 1 diabetes and migrants tend to establish an incidence of diabetes similar to that of the host population [45, 46]. Finland has the highest national incidence of type 1 diabetes (e.g. a hundredfold that of China) [47]. In countries with a lower incidence of type 1 diabetes, the increase in incidence has been more marked [48] whereas in high-prevalence countries it may have decelerated [49]. In parallel with a globally increased prevalence, the proportion of individuals with type 1 diabetes having the high-risk HLA$D R 3 / 4-D Q 2 / 8$ genotype has decreased [50].

Infectious agents are among the most extensively studied of the possible environmental triggers. Epidemiological, serological and histological studies, also in experimental animals, support the involvement of viral infections in the aetiology of type 1 diabetes. Proposed mechanisms include T cell crossreactivity between viruses and islet autoantigens or exposure of beta cell autoantigens to nearby inflammation [51]. Enteroviruses and rubella virus are commonly studied, although the link between congenital rubella infections and type 1 diabetes is controversial [52]. Coxsackie infection during pregnancy may induce beta cell autoimmunity in the mother [53] and may increase the risk for type 1 diabetes in the offspring $[54,55]$. Virus studies need to be related to the staging of type 1 diabetes.

A number of nutritional components have been suggested to modulate the risk of type 1 diabetes. Cow's milk has been associated with both the development of beta cell autoimmunity and progression to type 1 diabetes in children with beta cell autoimmunity [56]. Studies of disease risk in relation to the duration of breastfeeding and the introduction of cereals and solid foods in general to the diet have yielded inconsistent results [45]. Hydrolysed infant formula did not prevent the appearance of beta cell autoantibodies [57].

Observational findings suggest that vitamin D protects against type 1 diabetes by modulating the immune system. However, clinical trials have so far been unsuccessful [45].
Similarly, the anti-inflammatory properties of $n-3$ fatty acids have been suggested to influence the risk of autoimmunity. A prospective birth cohort study found no association between maternal long-chain $n-3$ fatty acid levels during pregnancy and the development of type 1 diabetes in offspring [58]. In one as-yet-unconfirmed report administration of probiotics during the first 27 days of life reduced the risk for a firstappearing beta cell autoantibody in children with the $H L A-D Q 2 / 8$ genotype [59].

Factors that increase the body's requirement for insulin, such as high levels of sugar, may hasten the progression to clinical onset of type 1 diabetes in persons with beta cell autoimmunity [60]. Accordingly, intake of high glycaemic index foods and sugar has been associated with progression to clinical onset in children with beta cell autoantibodies, but not with the development of islet autoimmunity per se [61].

Rapid longitudinal growth, puberty, trauma, low physical activity, being overweight and infections have also been proposed to increase beta cell stress and thereby hasten progression to clinical onset of diabetes in children with beta cell autoimmunity. Psychological stress may increase the probability of both autoimmunity and type 1 diabetes, possibly via increased cortisol, which would increase insulin resistance and directly modulate the immune system [45].

Overall, despite many environmental triggers being implicated in the pathogenesis of beta cell autoimmunity and type 1 diabetes, much of the research appears conflicting. Large, prospective studies of environmental determinants of type 1 diabetes and efforts to translate their findings into preventative interventions are ongoing [62].

\section{Stage 1: asymptomatic beta cell autoimmunity}

Beta cell autoantibodies The appearance of beta cell autoantibodies currently represents the earliest established sign of autoimmunity directed towards the pancreatic islet beta cells. Four primary types of islet autoantibodies are detected as markers of beta cell autoimmunity: those against GAD 65, insulin, insulinoma antigen-2 and zinc transporter 8 (which has arginine, glutamine, and tryptophan as variants) [50].

In longitudinal studies of genetically at-risk children followed from birth, beta cell autoantibodies have rarely been detected before the age of 6 months [2]. The peak incidence of the appearance of a first islet autoantibody was at age 9-24 months for IAA and about 36 months for GADA. IA-2A and ZnT8A rarely appeared as a first autoantibody and tended to occur later.

The presence of multiple autoantibodies greatly increases the probability for type 1 diabetes - $70 \%$ of diabetic individuals have three or four autoantibodies, while only $10 \%$ have a single autoantibody [63, 64]. About $96 \%$ of individuals are positive for at least one of these four autoantibodies and a 
number of further candidate autoantibodies have been identified [65].

The duration of stage 1 of type 1 diabetes pathogenesis may vary from a few months to decades. Older age at the appearance of islet autoimmunity, slower progression from single to multiple beta cell autoantibodies and lower IAA titres may predict a delayed clinical onset $[66,67]$. Loss of IAA reactivity in children with several autoantibodies was associated with delayed progression to clinical onset [68].

Conversely, in TEDDY, higher IAA and IA-2A titres, but not GADA titres, increased type 1 diabetes in the 5 years that followed the first islet autoantibody [69]. Persons with IA-2A $[70,71]$ and $\mathrm{ZnT} 8 \mathrm{~A}[71]$ tend to progress more rapidly to type 1 diabetes than persons without these autoantibodies. Autoantibody titres do not always increase closer to the time of diabetes onset [72]. Up to $60 \%$ of persons positive for a single autoantibody may revert to seronegativity [73] and patterns of antibody titres may vary without a clear prognostic significance [74].

A 10 year follow-up of children with multiple islet autoantibodies showed that the $H L A-D R 3-D Q 2 / D R 4-D Q 8$ genotype had a greater risk for diabetes than children with other HLA genotypes [75], yet smaller studies have failed to show that HLA genotype influences the rate of progression [76]. NonHLA SNPs may influence the rate of progression to clinical onset $[66,76]$.

The initiation of beta cell destruction Beta cell destruction has variously been modelled as a linear or an intermittently relapsing process. The limited human histological evidence available suggests that persistent inflammation of pancreatic islets (insulitis) is present in only a small proportion of nondiabetic, autoantibody-positive individuals and that insulitis emerges closer to the clinical onset $[77,78]$.

Peripheral $\mathrm{CD}^{+}$and $\mathrm{CD}^{+} \mathrm{T}$ cells with specificity for beta cell autoantigens are often found in persons at high risk of diabetes or in recently diagnosed individuals. Beta cell autoantibodies, long regarded as merely markers of the autoimmune process, may contribute through $\mathrm{B}$ cells presenting antigens to $\mathrm{CD}^{+}$and $\mathrm{CD}^{+}$T cells [79]. It is thought that cytotoxic $\mathrm{T}$ cells, helper $\mathrm{T}$ cells, natural killer cells and macrophages contribute to the actual destruction of beta cells [80]. While several modes of action have been proposed in the mouse [81, 82], the pathogenic pathway is less understood in humans. Recent studies of organ donors [77, 83-85] indicate that multiple autoantibodies and an expected proximity to clinical diagnosis was associated with insulitis. Hence, in contrast to the common belief that insulitis needs to precede islet autoantibodies, the latter may be present months to years before mononuclear cells invade the pancreatic islets.

Although B and T cell activity is a known key driver of beta cell destruction, the role of the innate immune system in type 1 diabetes is also recognised [86]. The activation of innate pattern-recognition receptors promotes the synthesis and release of proinflammatory mediators [87]. The relevance of the complement system to type 1 diabetes has been suggested by the association with HLA class III SNPs [35, 36]. Complement component $\mathrm{C} 4 \mathrm{~d}$ was found in the pancreas of $25 \%$ of individuals with type 1 diabetes, $7 \%$ of autoantibody-positive nondiabetic individuals and $2 \%$ of autoantibody-negative non-diabetic individuals [88].

Current evidence suggests that loss of function and destruction of beta cells begins after the onset of autoimmunity signalled by beta cell autoantibodies. Beta cell destruction may be precipitated by the innate immune system and inflammation, and activated autoreactive lymphocytes are believed to carry out most of the actual beta cell damage. Already in stage 1 of type 1 diabetes, fluctuations of insulin secretion may be detected, probably due to reversible beta cell stressors rather than beta cell death per se [89]. Once functional beta cell mass has declined sufficiently, an individual's blood glucose begins to deviate. The individual thus enters stage 2 of the progression towards manifest type 1 diabetes.

\section{Stage 2: asymptomatic beta cell autoimmunity with dysglycaemia}

At this stage, enough functional beta cell mass has been lost that biochemical tests may reveal impaired glucose tolerance. As yet, no symptoms develop.

Repeated, longitudinal GTTs in persons progressing towards clinical onset show a pattern of altered insulin and C-peptide secretion and reduced glucose clearance as beta cell mass declines [90]. An early sign of beta cell failure is a reduced early-phase insulin response during an IVGTT or OGTT [91].

During the decline of first-phase insulin and C-peptide responses, the late-phase insulin response (defined as insulin secretion after $30 \mathrm{~min}$ ) increases, so that the total AUCs for insulin and C-peptide over time remain essentially stable throughout much of the prodromal period. The maximal glucose excursions and the duration of elevated postprandial blood glucose during an OGTT increase as overt diabetes approaches [90]. Deterioration of insulin response measured as peak C-peptide and the $2 \mathrm{~h}$ glucose value during an OGTT seem to accelerate in the months before diabetes diagnosis $[92,93]$.

Decreasing glucose tolerance is often reflected by a gradually increasing $\mathrm{HbA}_{1 \mathrm{c}}$ within the reference range. Increase in $\mathrm{HbA}_{1 \mathrm{c}}$ may be used as a marker of high specificity but poor sensitivity for clinical onset [94]. Longitudinal measurements of random glucose values are less useful [95]. Markers such as fructosamine, 1,5-anhydroglucitol and glycated albumin reflect glycaemic control on a timescale intermediate to those of daily glucose and $\mathrm{HbA}_{1 \mathrm{c}}$ and could therefore potentially 
increase the sensitivity of beta cell function compared with $\mathrm{HbA}_{1 \mathrm{c}}$. All three markers are predictive of type 2 diabetes [96] but their utility for predicting type 1 diabetes has not been tested.

\section{Stage 3: symptomatic type 1 diabetes}

At the clinical onset of type 1 diabetes, remaining beta cells produce insufficient insulin to prevent persistent hyperglycaemia, with its classic symptoms of polyuria, polydipsia and polyphagia. Autopsy studies show a beta cell mass of about $10 \%$ of normal in individuals with recent-onset type 1 diabetes. However, as these studies are performed mostly in persons who died of diabetic ketoacidosis, this probably underestimates the remaining beta cell mass in most newly diagnosed individuals [97]. Indeed, those who are older at onset tend to have more beta cells than young children and loss of $40 \%$ of beta cells can be sufficient to induce symptoms in a 20-year-old person [98].

In agreement with these findings, one-third of young people maintain C-peptide levels within the reference range 1 year after diagnosis [99]. Children with higher preserved C-peptide levels tend to be older at diagnosis and have a higher ageadjusted BMI. When interpreting these data, one should bear in mind that participants in longitudinal investigations of atrisk individuals tend to be diagnosed with type 1 diabetes earlier in the disease course than individuals in the general population and therefore tend to have higher C-peptide levels [100].

Following the initiation of insulin treatment, about $80 \%$ of children and adolescents experience partial remission, with reduced insulin requirements. This is attributed to transiently improved insulin secretion and peripheral insulin sensitivity [50]. It is believed that the treatment of hyperglycaemia reverses beta cell exhaustion [101]. In the Diabetes Control and Complications Trial, aggressive treatment of hyperglycaemia was associated with preserved beta cell function [102]. In contrast, a more recent study failed to demonstrate preserved beta cell function in newly diagnosed individuals receiving intensified anti-hyperglycaemic therapy compared with those receiving current standards of care [103].

Retained beta cell function is associated with lower $\mathrm{HbA}_{1 \mathrm{c}}$ values and reduced probability of both long-term diabetic complications and severe hypoglycaemia [100]. Recent studies employing highly sensitive C-peptide assays suggest that individuals with long-term type 1 diabetes secrete residual amounts of insulin [104]. This is consistent with histological evidence that functional beta cells can be found in long-standing type 1 diabetes [105]. Insulitis may persist for years after diabetes onset but correlates negatively with duration of diabetes [78]. Ongoing insulitis seems to correlate with remaining beta cells, whereas persons without histological evidence of insulitis rarely have residual amounts of insulin [78].

Despite the presence of beta cells in some individuals with diabetes of long duration, the insulin response to OGTT deteriorates further after type 1 diabetes becomes symptomatic, suggesting continued beta cell loss. C-peptide response is reduced overall and glucose levels are elevated at 60,90 and $120 \mathrm{~min}$, but not at $30 \mathrm{~min}$, in children during repeat OGTTs within 3 months of an initial positive diagnostic OGTT [92]. Temporary remission following diagnosis notwithstanding, patients soon become dependent on exogenous insulin for survival.

\section{Novel biomarkers with potential to allow early prediction}

Emerging novel technologies provide opportunities for uncovering biomarkers that may predict beta cell autoimmunity and type 1 diabetes. These include transcriptomics, proteomics, metabolomics, intestinal microbiome DNA sequencing and beta cell-derived proteins and nucleic acids. In addition to biomarkers for the prediction of type 1 diabetes itself, predictors of angiopathic and neuropathic complications of the disease are being investigated [106].

Transcriptomics (study of patterns of gene expression) has shown promise for risk stratification of autoantibody-positive individuals [107]. It has been reported that a proinflammatory signature of gene expression is present both in individuals with recent-onset type 1 diabetes and in high-risk individuals who later progress to diabetes. In the latter group, the gene expression signature preceded the appearance of autoantibodies $[108,109]$. These studies point towards dysregulation of the innate immune system having potential as an early predictor of adaptive beta cell autoimmunity.

Proteomic studies have also suggested that patterns of immune dysregulation characterise type 1 diabetes [110]. Still, studies are few and much work remains to be done before proteomic hallmarks predictive of beta cell autoimmunity and type 1 diabetes are established.

Metabolomics techniques have shown that persons who progress to diabetes have different levels of certain lipids when compared with persons who remain non-diabetic [111]. There is evidence that these differences exist already in utero; altered lipid content of the umbilical cord may reflect a pathogenic pregnancy and an increased chance of developing type 1 diabetes at an earlier age. Cord blood phosphatidylcholines and phosphatidylethanolamines were significantly decreased in children diagnosed with type 1 diabetes before 4 years of age $[112,113]$.

In a longitudinal study, serum metabolite profiles were compared between children who were autoantibody-negative and remained healthy and those who progressed to clinical 
onset of type 1 diabetes [111]. The latter children showed already-reduced serum levels of succinic acid and phosphatidylcholine in the cord blood while triacylglycerols and antioxidant ether phospholipids were reduced during follow-up and proinflammatory lysophosphatidylcholines increased several months before the appearance of a first islet autoantibody. Specifically, before the appearance of IAA and GADA there was a decrease in ketoleucine and an increase in glutamic acid. Therefore, an early metabolic change preceding autoimmunity cannot be ruled out. At the time of clinical onset only specific phospholipids remained diminished as compared with matched non-progressors. The authors concluded that a reduction in choline-containing phospholipids in cord blood is associated with progression to type 1 diabetes but not with development of beta cell autoimmunity [111].

The human gut microbiome has altered significantly during the last century in response to changes in nutrition and the use of antibiotics, among other environmental factors. Studies so far suggest that the diversity of intestinal bacterial flora is reduced in autoantibody-positive persons who progress to type 1 diabetes. Alterations of the microbiome have not yet been demonstrated before the appearance of autoantibodies. The current evidence thus suggests that the microbiome may reflect the development of clinical disease in persons with demonstrable autoimmunity, but not the initiation of autoimmunity itself [114]. Mechanistically, it has been suggested that the microbiome affects innate immunity and may be linked to inflammatory serum signatures [87]. Studies on the role of the microbiome in type 1 diabetes are still at an early stage of development and have so far been observational.

Markers of T cell activation and beta cell destruction (such as beta cell-specific DNA, RNA and proteins) have been studied as indicators of increased diabetes risk and diabetes [115]. Nanoparticles have been used in MRI to visualise insulitis in individuals with recent-onset type 1 diabetes [116], and further studies of non-invasive radiological methods for insulitis are of interest.

Scores combining biochemical and clinical characteristics to predict the risk of type 1 diabetes have been derived from trials of high-risk individuals [117-119]. The Diabetes Prevention Trial Risk Score was developed through the Diabetes Prevention Trial 1, which included islet autoantibody-positive relatives of individuals with type 1 diabetes. The model was later tested in the TrialNet Natural History, in which 2 and 3 year chance for diabetes was found to be similar to that in the original cohort [120]. The models have not yet been validated in a general population.

'Omics' techniques and other novel biomarkers are still in their infancy for predicting the stages of type 1 diabetes. Validation studies across multiple, large cohorts are needed. Identifying persons in stages that precede beta cell autoimmunity and understanding the mechanisms of early stages may offer new opportunities for preventative interventions (Table 2).

\section{Current gaps in knowledge and possible future directions}

Despite significant advances in understanding type 1 diabetes, our grasp of the aetiology and pathogenesis and our ability to predict the disease is incomplete, as outlined below.

Variants of some 50 genes have been identified as affecting the risk for type 1 diabetes [121]. Research investigating how these genetic variants affect the progression through each of the three stages of type 1 diabetes is needed. Interactions between different genes, between genes and the environment and between different environmental factors need investigating.

Table 2 Established and emerging predictors of type 1 diabetes

\begin{tabular}{|c|c|c|c|}
\hline Predictor & Risk factor & $\begin{array}{l}\text { Detectable before } \\
\text { diagnosis }\end{array}$ & Reference \\
\hline HLA genotype & Certain HLA class II haplotypes; to a lesser extent, class I haplotypes & From gestation & {$[13,33]$} \\
\hline Non-HLA genotype & About 50 candidate genes & From gestation & {$[37]$} \\
\hline Beta cell-derived proteins and nucleic acids & Increased unmethylated INS DNA reflects beta cell death & Months to years & [89] \\
\hline Serum transcriptome & Proinflammatory pattern of gene expression & Months to years & {$[108]$} \\
\hline Serum proteome & Patterns of immune activation? & Unknown & {$[110]$} \\
\hline Serum metabolome & Reduced phosphatidylcholine & From gestation & [113] \\
\hline Gut microbiome & Decreased bacterial diversity & Unknown & {$[114]$} \\
\hline Autoantibodies & Risk increases with number of autoantibody types & Months to decades & {$[50]$} \\
\hline Minor autoantibodies & Found in fewer than $30 \%$ of individuals & Unknown & [123] \\
\hline $\mathrm{HbA}_{1 \mathrm{c}}$ & Increase from baseline & Months to years & [94] \\
\hline IVGTT/OGTT & Reduced early-phase insulin response and elevated postprandial glucose & Months to years & {$[90]$} \\
\hline Radiology & Pancreatic nanoparticle uptake indicating insulitis & Unknown & {$[116]$} \\
\hline
\end{tabular}


A major question is whether individuals destined to develop type 1 diabetes can be identified before the appearance of beta cell autoantibodies. Robust prediction of autoantibodies would seem an opportunity for new preventative strategies. Primary prevention with oral insulin has been attempted in newborns [122].

A number of minor autoantigens have been implicated in the pathogenesis of type 1 diabetes. Autoantigens are regarded as 'minor' when less than $30 \%$ of newly diagnosed type 1 diabetes persons exhibit autoantibodies. Many of these autoantibodies, found in the general population, are present in a higher proportion of persons with type 1 diabetes [123]. The natural history of minor autoantigens in type 1 diabetes, their contribution to the development of disease and their predictive value remains largely obscure.

A small proportion of individuals with type 1 diabetes are negative for all the major islet autoantibodies [124]. Further research needs to clarify whether these people were previously autoantibody-positive but then converted to seronegativity, whether they have an immune response against hitherto unidentified beta cell antigens or known minor autoantigens, or whether their condition represents a type of diabetes with an aetiology altogether different from that of type 1 diabetes.

Less is known about new-onset type 1 diabetes in adults than in children. The incidence is difficult to ascertain since many adults with type 1 diabetes will be misclassified as type 2 diabetes. In adults, GADA appear more frequently than other islet autoantibodies and symptoms following progressive insulin deficiency may appear more gradually $[125,126]$.

\section{Summary and conclusions}

In summary, genetic variation in the HLA region is the major determinant of diabetes risk at birth. It is now possible to study not only the genetic but also the environmental aetiology that may involve triggers causing the appearance of a first islet autoantibody, be it IAA in children with $H L A D R 4-D Q 8$ or GADA in children with $D R 3-D Q 2$. The mechanisms of the long-sought-after association between HLA and type 1 diabetes needs to be evaluated through the mechanisms of antigen presentation by HLA class II heterodimers. High-resolution sequencing and detailed mapping of the HLA region will be important to disclose gene-environmental interactions. The appearance of multiple islet autoantibodies strongly predicts the clinical onset of type 1 diabetes. In persons with multiple islet autoantibodies, progressive dysglycaemia signals increasing proximity to overt hyperglycaemia and clinical onset. It is likely that the three-stage model of type 1 diabetes will be updated and improved as beta cell autoimmunity and beta cell loss of function and destruction become better understood. Further risk stratification will allow the identification of individuals predestined to type 1 diabetes to allow preventative measures. Refined predictors of islet autoimmunity and type 1 diabetes may ultimately enable successful interventions to prevent the disease altogether.

Acknowledgements We thank the DiPiS and TEDDY children and their families for a never failing support and effort.

Funding Supported in part by the Swedish Research Council, the Swedish Diabetes Association, the National Institute of Diabetes and Digestive and Kidney Diseases (NIDDK; grant numbers DK63861 and UC4DK095300 and Contract No. HHSN267200700014C), National Institute of Allergy and Infectious Diseases (NIAID), National Institute of Child Health and Human Development (NICHD), National Institute of Environmental Health Sciences (NIEHS), JDRF, and Centers for Disease Control and Prevention (CDC).

Duality of interest The authors declare that there is no duality of interest associated with this manuscript.

Contribution statement Both authors were responsible for drafting the article and revising it critically for important intellectual content. Both authors approved the version to be published.

Open Access This article is distributed under the terms of the Creative Commons Attribution 4.0 International License (http:// creativecommons.org/licenses/by/4.0/), which permits unrestricted use, distribution, and reproduction in any medium, provided you give appropriate credit to the original author(s) and the source, provide a link to the Creative Commons license, and indicate if changes were made.

\section{References}

1. Insel RA, Dunne JL, Atkinson MA et al (2015) Staging presymptomatic type 1 diabetes: a scientific statement of JDRF, the Endocrine Society, and the American Diabetes Association. Diabetes Care 38:1964-1974

2. Krischer JP, Lynch KF, Schatz DA et al (2015) The 6 year incidence of diabetes-associated autoantibodies in genetically at-risk children: the TEDDY study. Diabetologia 58:980-987

3. Ilonen J, Hammais A, Laine AP et al (2013) Patterns of $\beta$-cell autoantibody appearance and genetic associations during the first years of life. Diabetes 62:3636-3640

4. Ziegler AG, Hummel M, Schenker M, Bonifacio E (1999) Autoantibody appearance and risk for development of childhood diabetes in offspring of parents with type 1 diabetes: the 2-year analysis of the German BABYDIAB Study. Diabetes 48:460-468

5. Dahlquist G, Blom L, Holmgren G et al (1985) The epidemiology of diabetes in Swedish children 0-14 years - a six-year prospective study. Diabetologia 28:802-808

6. Pociot F, Lernmark A (2016) Genetic risk factors for type 1 diabetes. Lancet 387:2331-2339

7. Bonifacio E, Hummel M, Walter M, Schmid S, Ziegler AG (2004) IDDM1 and multiple family history of type 1 diabetes combine to identify neonates at high risk for type 1 diabetes. Diabetes Care 27:2695-2700

8. Hyttinen V, Kaprio J, Kinnunen L, Koskenvuo M, Tuomilehto J (2003) Genetic liability of type 1 diabetes and the onset age among 22,650 young Finnish twin pairs: a nationwide follow-up study. Diabetes 52:1052-1055 
9. Gupta B, Hawkins RD (2015) Epigenomics of autoimmune diseases. Immunol Cell Biol 93:271-276

10. Rich SS, Akolkar B, Concannon P et al (2009) Overview of the type I diabetes genetics consortium. Genes Immun 10(Suppl 1): S1-S4

11. Torn C, Hadley D, Lee HS et al (2015) Role of type 1 diabetesassociated SNPs on risk of autoantibody positivity in the TEDDY study. Diabetes 64:1818-1829

12. Trowsdale J, Knight JC (2013) Major histocompatibility complex genomics and human disease. Annu Rev Genomics Hum Genet 14:301-323

13. Noble JA, Valdes AM, Cook M, Klitz W, Thomson G, Erlich HA (1996) The role of HLA class II genes in insulin-dependent diabetes mellitus: molecular analysis of 180 Caucasian, multiplex families. Am J Hum Genet 59:1134-1148

14. Nguyen C, Varney MD, Harrison LC, Morahan G (2013) Definition of high-risk type 1 diabetes HLA-DR and HLA-DQ types using only three single nucleotide polymorphisms. Diabetes 62:2135-2140

15. Thomson G, Valdes AM, Noble JA et al (2007) Relative predispositional effects of HLA class II DRB1-DQB1 haplotypes and genotypes on type 1 diabetes: a meta-analysis. Tissue Antigens 70:110-127

16. Bingley PJ, Christie MR, Bonifacio E et al (1994) Combined analysis of autoantibodies improves prediction of IDDM in islet cell antibody-positive relatives. Diabetes 43:1304-1310

17. Maclaren NK, Lan MS, Schatz D, Malone J, Notkins AL, Krischer $\mathrm{J}$ (2003) Multiple autoantibodies as predictors of type 1 diabetes in a general population. Diabetologia 46:873-874

18. Ziegler AG, Rewers M, Simell O et al (2013) Seroconversion to multiple islet autoantibodies and risk of progression to diabetes in children. JAMA 309:2473-2479

19. De Grijse J, Asanghanwa M, Nouthe B et al (2010) Predictive power of screening for antibodies against insulinoma-associated protein 2 beta (IA- $2 \beta$ ) and zinc transporter- 8 to select first-degree relatives of type 1 diabetic patients with risk of rapid progression to clinical onset of the disease: implications for prevention trials. Diabetologia 53:517-524

20. Yu L, Boulware DC, Beam CA et al (2012) Zinc transporter-8 autoantibodies improve prediction of type 1 diabetes in relatives positive for the standard biochemical autoantibodies. Diabetes Care 35:1213-1218

21. Graham J, Hagopian WA, Kockum I et al (2002) Genetic effects on age-dependent onset and islet cell autoantibody markers in type 1 diabetes. Diabetes 51:1346-1355

22. Knip M, Kukko M, Kulmala P et al (2002) Humoral beta-cell autoimmunity in relation to HLA-defined disease susceptibility in preclinical and clinical type 1 diabetes. Am J Med Genet 115: $48-54$

23. Andersson C, Larsson K, Vaziri-Sani F et al (2011) The three ZNT8 autoantibody variants together improve the diagnostic sensitivity of childhood and adolescent type 1 diabetes. Autoimmunity 44:394 405

24. Delli AJ, Vaziri-Sani F, Lindblad B et al (2012) Zinc transporter 8 autoantibodies and their association with SLC30A8 and HLA-DQ genes differ between immigrant and Swedish patients with newly diagnosed type 1 diabetes in the Better Diabetes Diagnosis study. Diabetes 61:2556-2564

25. Erlich H, Valdes AM, Noble J et al (2008) HLA DR-DQ haplotypes and genotypes and type 1 diabetes risk: analysis of the type 1 diabetes genetics consortium families. Diabetes 57:1084 1092

26. Lambert AP, Gillespie KM, Thomson G et al (2004) Absolute risk of childhood-onset type 1 diabetes defined by human leukocyte antigen class II genotype: a population-based study in the United Kingdom. J Clin Endocrinol Metab 89:4037-4043
27. Laine AP, Holmberg H, Nilsson A et al (2007) Two insulin gene single nucleotide polymorphisms associated with type 1 diabetes risk in the Finnish and Swedish populations. Dis Markers 23:139 145

28. Nelson WC, Pyo CW, Vogan D et al (2015) An integrated genotyping approach for HLA and other complex genetic systems. Hum Immunol 76:928-938

29. Smith AG, Pyo CW, Nelson W et al (2014) Next generation sequencing to determine HLA class II genotypes in a cohort of hematopoietic cell transplant patients and donors. Hum Immunol 75:1040-1046

30. Zhao LP, Alshiekh S, Zhao M et al (2016) Next-generation sequencing reveals that HLA-DRB3, -DRB4, and -DRB5 may be associated with islet autoantibodies and risk for childhood type 1 diabetes. Diabetes 65:710-718

31. Erlich HA, Valdes AM, McDevitt S et al (2013) Next generation sequencing reveals the association of DRB3*02:02 with type I diabetes. Diabetes 62:2618-2622

32. Valdes AM, Thomson G, Graham J et al (2005) D6S265*15 marks a DRB $1 * 15$, DQB1*0602 haplotype associated with attenuated protection from type 1 diabetes mellitus. Diabetologia 48: 2540-2543

33. Noble JA, Valdes AM, Varney MD et al (2010) HLA class I and genetic susceptibility to type 1 diabetes: results from the Type 1 Diabetes Genetics Consortium. Diabetes 59:2972-2979

34. Noble JA, Erlich HA (2012) Genetics of type 1 diabetes. Cold Spring Harb Perspect Med 2:a007732

35. Valdes AM, Thomson G, Barcellos LF (2010) Genetic variation within the HLA class III influences T1D susceptibility conferred by high-risk HLA haplotypes. Genes Immun 11:209-218

36. Torn C, Liu X, Hagopian W et al (2016) Complement gene variants in relation to autoantibodies to beta cell specific antigens and type 1 diabetes in the TEDDY Study. Sci Report 6:27887

37. Maziarz M, Hagopian W, Palmer JP et al (2015) Non-HLA type 1 diabetes genes modulate disease risk together with HLA-DQ and islet autoantibodies. Genes Immun 16:541-551

38. Bergholdt R, Brorsson C, Palleja A et al (2012) Identification of novel type 1 diabetes candidate genes by integrating genome-wide association data, protein-protein interactions, and human pancreatic islet gene expression. Diabetes 61:954-962

39. Ueda H, Howson JM, Esposito L et al (2003) Association of the Tcell regulatory gene CTLA4 with susceptibility to autoimmune disease. Nature 423:506-511

40. Pociot F, Akolkar B, Concannon P et al (2010) Genetics of type 1 diabetes: what's next? Diabetes 59:1561-1571

41. Cotsapas C, Voight BF, Rossin E et al (2011) Pervasive sharing of genetic effects in autoimmune disease. PLoS Genet 7:e1002254

42. Parkes M, Cortes A, van Heel DA, Brown MA (2013) Genetic insights into common pathways and complex relationships among immune-mediated diseases. Nat Rev Genet 14:661-673

43. Zheng W, She JX (2005) Genetic association between a lymphoid tyrosine phosphatase (PTPN22) and type 1 diabetes. Diabetes 54: 906-908

44. Bjornvold M, Undlien DE, Joner G et al (2008) Joint effects of HLA, INS, PTPN22 and CTLA4 genes on the risk of type 1 diabetes. Diabetologia 51:589-596

45. Rewers M, Ludvigsson $\mathrm{J}$ (2016) Environmental risk factors for type 1 diabetes. Lancet 387:2340-2348

46. Delli AJ, Lindblad B, Carlsson A et al (2010) Type 1 diabetes patients born to immigrants to Sweden increase their native diabetes risk and differ from Swedish patients in HLA types and islet autoantibodies. Pediatr Diabetes 11:513-520

47. Karvonen M, Viik-Kajander M, Moltchanova E, Libman I, LaPorte R, Tuomilehto J (2000) Incidence of childhood type 1 diabetes worldwide. Diabetes Mondiale (DiaMond) Project Group. Diabetes Care 23:1516-1526 
48. Zhao Z, Sun C, Wang C et al (2014) Rapidly rising incidence of childhood type 1 diabetes in Chinese population: epidemiology in Shanghai during 1997-2011. Acta Diabetol 51:947-953

49. Berhan Y, Waernbaum I, Lind T, Mollsten A, Dahlquist G, Swedish Childhood Diabetes Study G (2011) Thirty years of prospective nationwide incidence of childhood type 1 diabetes: the accelerating increase by time tends to level off in Sweden. Diabetes 60:577-581

50. Couper JJ, Haller MJ, Ziegler AG et al (2014) ISPAD Clinical Practice Consensus Guidelines 2014. Phases of type 1 diabetes in children and adolescents. Pediatr Diabetes 15(Suppl 20):18-25

51. Boettler T, von Herrath M (2011) Protection against or triggering of type 1 diabetes? Different roles for viral infections. Expert Rev Clin Immunol 7:45-53

52. Gale EA (2008) Congenital rubella: citation virus or viral cause of type 1 diabetes? Diabetologia 51:1559-1566

53. Resic Lindehammer S, Honkanen H, Nix WA et al (2012) Seroconversion to islet autoantibodies after enterovirus infection in early pregnancy. Viral Immunol 25:254-261

54. Hyoty H, Hiltunen M, Knip M et al (1995) A prospective study of the role of coxsackie B and other enterovirus infections in the pathogenesis of IDDM. Child Diabetes Finl (DiMe) Study Group Diabetes 44:652-657

55. Dahlquist G, Frisk G, Ivarsson SA, Svanberg L, Forsgren M, Diderholm H (1995) Indications that maternal coxsackie B virus infection during pregnancy is a risk factor for childhood-onset IDDM. Diabetologia 38:1371-1373

56. Lamb MM, Miller M, Seifert JA et al (2015) The effect of childhood cow's milk intake and HLA-DR genotype on risk of islet autoimmunity and type 1 diabetes: the Diabetes Autoimmunity Study in the Young. Pediatr Diabetes 16:31-38

57. Knip M, Akerblom HK, Becker D et al (2014) Hydrolyzed infant formula and early beta-cell autoimmunity: a randomized clinical trial. JAMA 311:2279-2287

58. Sorensen IM, Joner G, Jenum PA, Eskild A, Stene LC (2012) Serum long chain n-3 fatty acids (EPA and DHA) in the pregnant mother are independent of risk of type 1 diabetes in the offspring. Diabetes Metab Res Rev 28:431-438

59. Uusitalo U, Liu X, Yang J et al (2016) Association of early exposure of probiotics and islet autoimmunity in the TEDDY study. JAMA Pediatr 170:20-28

60. Dahlquist G (2006) Can we slow the rising incidence of childhood-onset autoimmune diabetes? The overload hypothesis. Diabetologia 49:20-24

61. Lamb MM, Frederiksen B, Seifert JA, Kroehl M, Rewers M, Norris JM (2015) Sugar intake is associated with progression from islet autoimmunity to type 1 diabetes: the Diabetes Autoimmunity Study in the Young. Diabetologia 58:2027-2034

62. Skyler JS (2013) Primary and secondary prevention of type 1 diabetes. Diabet Med 30:161-169

63. Bingley PJ (2010) Clinical applications of diabetes antibody testing. J Clin Endocrinol Metab 95:25-33

64. Andersson C, Kolmodin M, Ivarsson SA et al (2013) Islet cell antibodies (ICA) identify autoimmunity in children with new onset diabetes mellitus negative for other islet cell antibodies. Pediatr Diabetes 15:336-344

65. Wenzlau JM, Hutton JC (2013) Novel diabetes autoantibodies and prediction of type 1 diabetes. Curr Diab Rep 13:608-615

66. Steck AK, Dong F, Waugh K et al (2016) Predictors of slow progression to diabetes in children with multiple islet autoantibodies. J Autoimmun 72:113-117

67. Steck AK, Johnson KJ, Barriga D et al (2011) Age of islet autoantibody appearance and mean levels of insulin, but not GAD or IA-2 autoantibodies, predict age of diagnosis of type 1 diabetes: diabetes autoimmunity study in the young. Diabetes Care 34: 1397-1399
68. Endesfelder D, Hagen M, Winkler C et al (2016) A novel approach for the analysis of longitudinal profiles reveals delayed progression to type 1 diabetes in a subgroup of multiple-isletautoantibody-positive children. Diabetologia 59:2172-2180

69. Steck AK, Vehik K, Bonifacio E et al (2015) Predictors of progression from the appearance of islet autoantibodies to early childhood diabetes: The Environmental Determinants of Diabetes in the Young (TEDDY). Diabetes Care 38:808-813

70. Decochez K, De Leeuw IH, Keymeulen B et al (2002) IA-2 autoantibodies predict impending type I diabetes in siblings of patients. Diabetologia 45:1658-1666

71. Gorus FK, Balti EV, Vermeulen I et al (2013) Screening for insulinoma antigen 2 and zinc transporter 8 autoantibodies: a cost-effective and age-independent strategy to identify rapid progressors to clinical onset among relatives of type 1 diabetic patients. Clin Exp Immunol 171:82-90

72. Vehik K, Lynch KF, Schatz DA et al (2016) Reversion of beta-cell autoimmunity changes risk of type 1 diabetes: TEDDY study. Diabetes Care 39:1535-1542

73. Knip M, Korhonen S, Kulmala P et al (2010) Prediction of type 1 diabetes in the general population. Diabetes Care 33:1206-1212

74. Bonifacio E (2015) Predicting type 1 diabetes using biomarkers. Diabetes Care 38:989-996

75. Decochez K, Truyen I, van der Auwera B et al (2005) Combined positivity for HLA DQ2/DQ8 and IA-2 antibodies defines population at high risk of developing type 1 diabetes. Diabetologia 48: 687-694

76. Achenbach P, Hummel M, Thumer L, Boerschmann H, Hofelmann D, Ziegler AG (2013) Characteristics of rapid vs slow progression to type 1 diabetes in multiple islet autoantibodypositive children. Diabetologia 56:1615-1622

77. Wiberg A, Granstam A, Ingvast S et al (2015) Characterization of human organ donors testing positive for type 1 diabetes-associated autoantibodies. Clin Exp Immunol 182:278-288

78. Campbell-Thompson M, Fu A, Kaddis JS et al (2016) Insulitis and $\beta$-cell mass in the natural history of type 1 diabetes. Diabetes 65 : 719-731

79. van Belle TL, Coppieters KT, von Herrath MG (2011) Type 1 diabetes: etiology, immunology, and therapeutic strategies. Physiol Rev 91:79-118

80. Lehuen A, Diana J, Zaccone P, Cooke A (2010) Immune cell crosstalk in type 1 diabetes. Nat Rev Immunol 10:501-513

81. Benoist C, Mathis D (1997) Cell death mediators in autoimmune diabetes - no shortage of suspects. Cell 89:1-3

82. Mathis D, Vence L, Benoist C (2001) Beta-cell death during progression to diabetes. Nature 414:792-798

83. In't Veld P, Lievens D, De Grijse J et al (2007) Screening for insulitis in adult autoantibody-positive organ donors. Diabetes 56:2400-2404

84. Campbell-Thompson ML, Montgomery EL, Foss RM, et al. (2012) Collection protocol for human pancreas. J Vis Exp 63:e4039

85. Pugliese A, Yang M, Kusmarteva I et al (2014) The Juvenile Diabetes Research Foundation Network for Pancreatic Organ Donors with Diabetes (nPOD) program: goals, operational model and emerging findings. Pediatr Diabetes 15:1-9

86. Eizirik DL, Colli ML, Ortis F (2009) The role of inflammation in insulitis and $\beta$-cell loss in type 1 diabetes. Nat Rev Endocrinol 5: 219-226

87. Cabrera SM, Henschel AM, Hessner MJ (2016) Innate inflammation in type 1 diabetes. Transl Res 167:214-227

88. Rowe P, Wasserfall C, Croker B et al (2013) Increased complement activation in human type 1 diabetes pancreata. Diabetes Care 36:3815-3817

89. Herold KC, Usmani-Brown S, Ghazi T et al (2015) $\beta$ cell death and dysfunction during type 1 diabetes development in at-risk individuals. J Clin Invest 125:1163-1173 
90. Sosenko JM, Skyler JS, Herold KC, Palmer JP, Type 1 Diabetes TrialNet Study Group, Diabetes Prevention Trial-Type 1 Study Group (2012) The metabolic progression to type 1 diabetes as indicated by serial oral glucose tolerance testing in the diabetes prevention trial-type 1. Diabetes 61:1331-1337

91. Greenbaum CJ, Cuthbertson D, Krischer JP, Diabetes Prevention Trial of Type 1 Diabetes Study Group (2001) Type I diabetes manifested solely by 2 -h oral glucose tolerance test criteria. Diabetes 50:470-476

92. Sosenko JM, Palmer JP, Rafkin-Mervis L et al (2008) Glucose and C-peptide changes in the perionset period of type 1 diabetes in the diabetes prevention trial-type 1. Diabetes Care 31:2188-2192

93. Ferrannini E, Mari A, Nofrate V, Sosenko JM, Skyler JS, DPT-1 Study Group (2010) Progression to diabetes in relatives of type 1 diabetic patients: mechanisms and mode of onset. Diabetes 59: 679-685

94. Vehik K, Cuthbertson D, Boulware D et al (2012) Performance of $\mathrm{HbA} 1 \mathrm{c}$ as an early diagnostic indicator of type 1 diabetes in children and youth. Diabetes Care 35:1821-1825

95. Stene LC, Barriga K, Hoffman M et al (2006) Normal but increasing hemoglobin A1c levels predict progression from islet autoimmunity to overt type 1 diabetes: Diabetes Autoimmunity Study in the Young (DAISY). Pediatr Diabetes 7:247-253

96. Juraschek SP, Steffes MW, Miller ER 3rd, Selvin E (2012) Alternative markers of hyperglycemia and risk of diabetes. Diabetes Care 35:2265-2270

97. Matveyenko AV, Butler PC (2008) Relationship between $\beta$-cell mass and diabetes onset. Diabetes Obes Metab 10:23-31

98. Klinke DJ II (2008) Extent of beta cell destruction is important but insufficient to predict the onset of type 1 diabetes mellitus. PLoS One 3:e1374

99. Greenbaum CJ, Anderson AM, Dolan LM et al (2009) Preservation of $\beta$-cell function in autoantibody-positive youth with diabetes. Diabetes Care 32:1839-1844

100. Steffes MW, Sibley S, Jackson M, Thomas W (2003) $\beta$-Ccell function and the development of diabetes-related complications in the diabetes control and complications trial. Diabetes Care 26: 832-836

101. Chmelova H, Cohrs CM, Chouinard JA et al (2015) Distinct roles of $\beta$-cell mass and function during type 1 diabetes onset and remission. Diabetes 64:2148-2160

102. The Diabetes Control and Complications Trial Research Group (1998) Effect of intensive therapy on residual $\beta$-cell function in patients with type 1 diabetes in the diabetes control and complications trial. A randomized, controlled trial. Ann Intern Med 128: 517-523

103. Buckingham B, Beck RW, Ruedy KJ et al (2013) Effectiveness of early intensive therapy on $\beta$-cell preservation in type 1 diabetes. Diabetes Care 36:4030-4035

104. Oram RA, McDonald TJ, Shields BM et al (2015) Most people with long-duration type 1 diabetes in a large population-based study are insulin microsecretors. Diabetes Care 38:323-328

105. Meier JJ, Bhushan A, Butler AE, Rizza RA, Butler PC (2005) Sustained beta cell apoptosis in patients with long-standing type 1 diabetes: indirect evidence for islet regeneration? Diabetologia 48:2221-2228

106. Bjornstad P, Maahs DM (2015) Diabetes complications in childhood diabetes-new biomarkers and technologies. Curr Pediatr Rep 3:177-186

107. Jin Y, Sharma A, Bai S et al (2014) Risk of type 1 diabetes progression in islet autoantibody-positive children can be further stratified using expression patterns of multiple genes implicated in peripheral blood lymphocyte activation and function. Diabetes 63:2506-2515

108. Wang X, Jia S, Geoffrey R, Alemzadeh R, Ghosh S, Hessner MJ (2008) Identification of a molecular signature in human type 1 diabetes mellitus using serum and functional genomics. J Immunol 180:1929-1937

109. Kallionpaa H, Elo LL, Laajala E et al (2014) Innate immune activity is detected prior to seroconversion in children with HLAconferred type 1 diabetes susceptibility. Diabetes 63:2402-2414

110. Zhang Q, Fillmore TL, Schepmoes AA et al (2013) Serum proteomics reveals systemic dysregulation of innate immunity in type 1 diabetes. J Exp Med 210:191-203

111. Oresic M, Simell S, Sysi-Aho M et al (2008) Dysregulation of lipid and amino acid metabolism precedes islet autoimmunity in children who later progress to type 1 diabetes. J Exp Med 205: 2975-2984

112. La Torre D, Seppanen-Laakso T, Larsson HE et al (2013) Decreased cord-blood phospholipids in young age-at-onset type 1 diabetes. Diabetes 62:3951-3956

113. Oresic M, Gopalacharyulu P, Mykkanen J et al (2013) Cord serum lipidome in prediction of islet autoimmunity and type 1 diabetes. Diabetes 62:3268-3274

114. Knip M, Siljander H (2016) The role of the intestinal microbiota in type 1 diabetes mellitus. Nat Rev Endocrinol 12:154-167

115. Watkins RA, Evans-Molina C, Blum JS, DiMeglio LA (2014) Established and emerging biomarkers for the prediction of type 1 diabetes: a systematic review. Transl Res 164:110-121

116. Gaglia JL, Harisinghani M, Aganj I et al (2015) Noninvasive mapping of pancreatic inflammation in recent-onset type-1 diabetes patients. Proc Natl Acad Sci U S A 112:2139-2144

117. Sosenko JM, Krischer JP, Palmer JP et al (2008) A risk score for type 1 diabetes derived from autoantibody-positive participants in the diabetes prevention trial-type 1. Diabetes Care 31:528-533

118. Xu P, Beam CA, Cuthbertson D et al (2012) Prognostic accuracy of immunologic and metabolic markers for type 1 diabetes in a high-risk population: receiver operating characteristic analysis. Diabetes Care 35:1975-1980

119. Mrena S, Virtanen SM, Laippala P et al (2006) Models for predicting type 1 diabetes in siblings of affected children. Diabetes Care 29:662-667

120. Sosenko JM, Skyler JS, Palmer JP, The Diabetes Type 1 TrialNet and Diabetes Prevention Trial-Type 1 Study Groups (2015) The development, validation, and utility of the diabetes prevention trial-type 1 risk score (DPTRS). Curr Diab Rep 15:49

121. Cooper JD, Howson JM, Smyth D et al (2012) Confirmation of novel type 1 diabetes risk loci in families. Diabetologia 55:9961000

122. Bonifacio E, Ziegler AG, Klingensmith $G$ et al (2015) Effects of high-dose oral insulin on immune responses in children at high risk for type 1 diabetes: the Pre-POINT randomized clinical trial. JAMA 313:1541-1549

123. Hirai H, Miura J, Hu Y et al (2008) Selective screening of secretory vesicle-associated proteins for autoantigens in type 1 diabetes: VAMP2 and NPY are new minor autoantigens. Clin Immunol 127: 366-374

124. Hameed S, Ellard S, Woodhead HJ et al (2011) Persistently autoantibody negative (PAN) type 1 diabetes mellitus in children. Pediatr Diabetes 12:142-149

125. Hawa MI, Kolb H, Schloot N et al (2013) Adult-onset autoimmune diabetes in Europe is prevalent with a broad clinical phenotype: action LADA 7. Diabetes Care 36:908-913

126. Chiang JL, Kirkman MS, Laffel LM, Peters AL, Type 1 Diabetes Sourcebook Authors (2014) Type 1 diabetes through the life span: a position statement of the American Diabetes Association. Diabetes Care 37:2034-2054

127. Carlsson A, Kockum I, Lindblad B et al (2012) Low risk HLA-DQ and increased body mass index in newly diagnosed type 1 diabetes children in the Better Diabetes Diagnosis study in Sweden. Int J Obes 36:718-724 